\title{
Future Dining Table: Dish Recommendation Based on Dining Activity Recognition
}

\author{
Tomoo Inoue \\ University of Tsukuba, Graduate School of Library, Information and Media Studies, \\ Kasuga 1-2, Tsukuba 305-8550 Japan \\ inouedslis.tsukuba.ac.jp
}

\begin{abstract}
Dining table is one of the environments that remain to be explored by information technology and that could be important for happy and healthy life of everybody. We have been studying the Future Dining Table system, dining environment of the future. The system features the real time recognition of dining activity, which is represented by the history of the hand movement to the dishes on the table. The history of dining actions is used to know the current status of dining. Currently the system recommends additional dishes according to the dining status. It is expected to be useful as a substitute of a food server in the age of labor shortage.
\end{abstract}

Keywords: dining computing, tabletop interaction, physical computing, activity recognition, food service.

\section{Introduction}

Information and communication technologies (ICT) have been positively applied in almost all fields. Because it is known that the wide use of ICT in a nation is closely related to the competency of the nation, ICT use in all fields has been promoted [1]. ICT is now in our daily life and is changing it. The major goal of ICT use has been the pursuit of efficiency and competency in business so far. We think it could also contribute to the pursuit of happiness and quality of life. Because eating is clearly indispensable for our life and closely connected to the feeling of happiness and the quality of life, application of ICT to eating activity is significant to our life and is likely to improve eating environment.

In this paper, we propose Future Dining Table as an example of the realization of the idea of eating environment innovation by ICT. The Future Dining Table recommends dishes to a user. The situation of the system use is assumed in a restaurant or typically in a Japanese pub where many dishes are ordered during dining. It recognizes dining action in real time. Dining action is recognized as a hand movement with chopsticks to the dishes on the table. The system stores the history of dining actions and uses it to know current status of dining. It is used to know whether the user is in the beginning of dining or is in the middle or is in the end, for example. According to the dining status, the system recommends the user the dishes that would fit to the current meal in the right timing for additional order. 
Considering the recent and future shortage of labor supply, it will become more difficult to keep good employees who are capable of recommending another dish which matches the dining status of the customers. The system is expected to be useful as a substitute of a food server in such situation.

In this paper, the chapters are composed in the following way. Related research is described in Chapter 2. The system is proposed in Chapter 3. Brief evaluation of the recognition element of the system is described in Chapter 4. Conclusion is given in Chapter 5.

\section{Related Research}

\subsection{Tabletop Interface, Use of Physical Objects and Its History}

People live and act in the physical world. They use various physical objects everyday. Tangible User Interface (TUI) uses physical objects as the user interface, and is thus known as more natural and intuitive way of interacting with computers [2]. Methods of information display on a table have been researched [3][4] because a table is often used when working on something. They are called tabletop interfaces. People put physical objects on a table and use them for many tasks. Thus table interface is closely related to TUI.

The proposed system falls on to the tabletop interface in the ubiquitous computing environment as well as a type of TUI. Dining activity includes the use of dishes, physical objects, on a table.

Because one of the features of a computer is that it can store information, command history of a user or various logs have been often used. For example, they are used for the adaptive support of a user or for the marketing of an Internet shop. As such, use of history information has been popular in computer systems. Although TUI and physical computing has been common, use of history in physical computing has not been exploited very much. One of the examples is a collaborative learning support system that multiple users operate multiple cubes on a touch-sensing table. In this system, history of who operates which cube is shown to the users [10]. However, this system only shows who has not touched which cube yet. Also, its usefulness is not very clear.

Dining activity can be viewed as operating history of dishes. Use of the history enables a system to recognize dining status of a user, not just a beginning and ending of dining.

There are common ways of recognizing physical objects by a computer. Use of visual markers such as barcodes is one of the easy and robust ways. For example, the Interactive Textbook which is one of the applications of the EnhancedDesk uses a textbook. Pages of the textbook are recognized by the barcodes that are printed on the corners of the pages [5]. SmartSkin is an example of other ways of recognition. It is a table where networked electrodes are embedded. It recognizes location of a hand or a physical object with a piece of metal on the table by detecting the capacitance change [6]. Although simple visual markers are used in our current system, dining table is one of the good environments to utilize these preceding studies. 


\subsection{Dining Recognition}

"Sixth dish" is a system to help interpersonal communication during dining. It projects pictures on vacant dishes from above so that pictures give clues to start conversation [7]. This research supports meal times in terms of communication but it does not use dining status or a user's behavior.

In welfare and medical care, meal has been recorded for management of health. This record is typically a written memorandum showing the given menu or sometimes the remains after meal. Because making a written meal record is time consuming and is not easy when there are many clients, automatic recording of meal has been researched in welfare information technology.

Recognition of dining behavior in a video has been proposed. It uses the video of a dining room to detect a hand movement and recognizes eating by applying hidden Markov model [8]. It does not recognize what the diners eat and the order of eating things.

An eating monitoring system has been proposed. This system uses dishes with RFID tags and a tray with a RFID reader and a load meter and pressure sensors. It can measure every step of weight reduction of food. What and how much it was eaten can be recognized. From the analysis of eating pattern with the system, it has been suggested that there is a stable eating pattern in the same person and eating patterns are different between different persons [9]. Though the system recognizes detailed reduction of food, it does not concern about the behavior of a user.

We plan to improve dining environment in not only recommending another dish, but other services such as communication support in the future. Because of this, behavior recognition of a user is necessary. In this assumption, we still like to recognize what food and how much a user eat on the way of the dining for providing fine adaptive service.

\subsection{Future Role of ICT Use in the Society}

Until recently, major part of the ICT research has pursued economical effectiveness and efficiency. There has not been amount of research on ICT use for happiness, good feelings or for the mental quality of life. However, there is a trend to pursue mental value as well as economical value recently. For example, Japan has turned its helm from being "a nation of economic power" to being "a nation with intellectual presence" [11]. Norman proposed importance of esthetic and emotional value of things in contrast with usability of things in his book published in 2004 [12]. The Workshop on Designing Cute Interactive Media that was held in 2008 focused its attention on the effects of cuteness, i.e. mental value of human, of interface agents or other things on user experience [13].

Our research is heading toward increasing mental value with the application of ICT in our daily life, although the proposed system is only a first step toward this goal and thus is not directly related to the quality of life yet.

\section{Future Dining Table}

Despite the prevalence of ICT in many fields, dining environment is one of the few that has not changed much. One of the few well known examples is RFID tagged dishes for calorie calculation or for checkout in cafeteria. So there is room for innovation. 


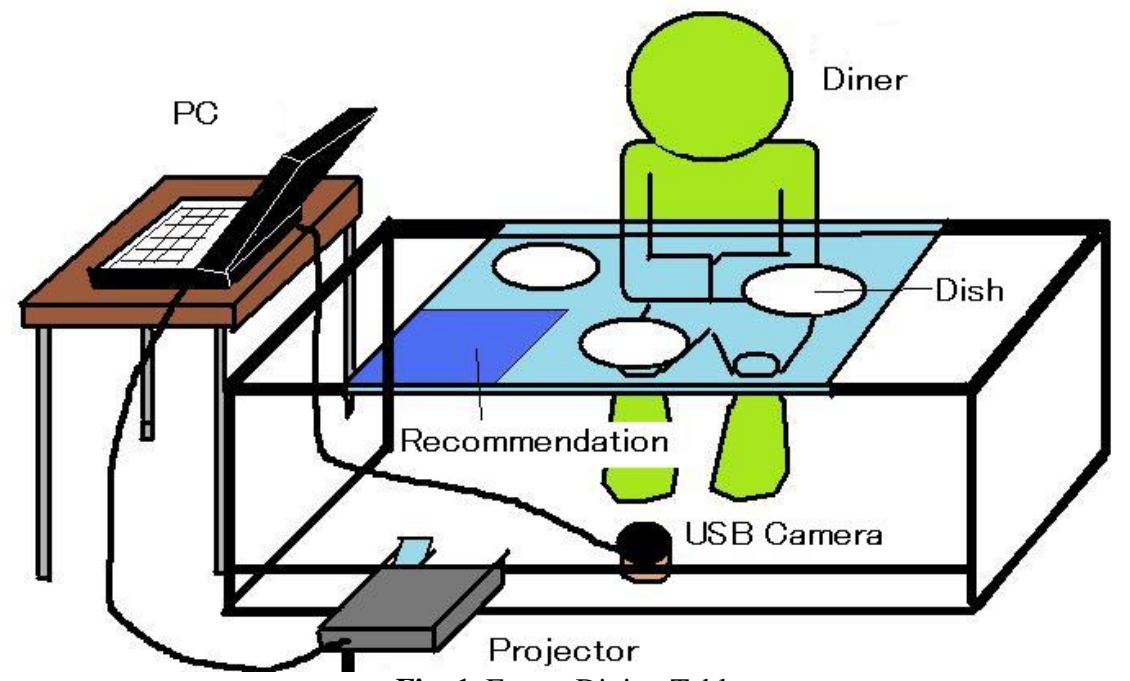

Fig. 1. Future Dining Table

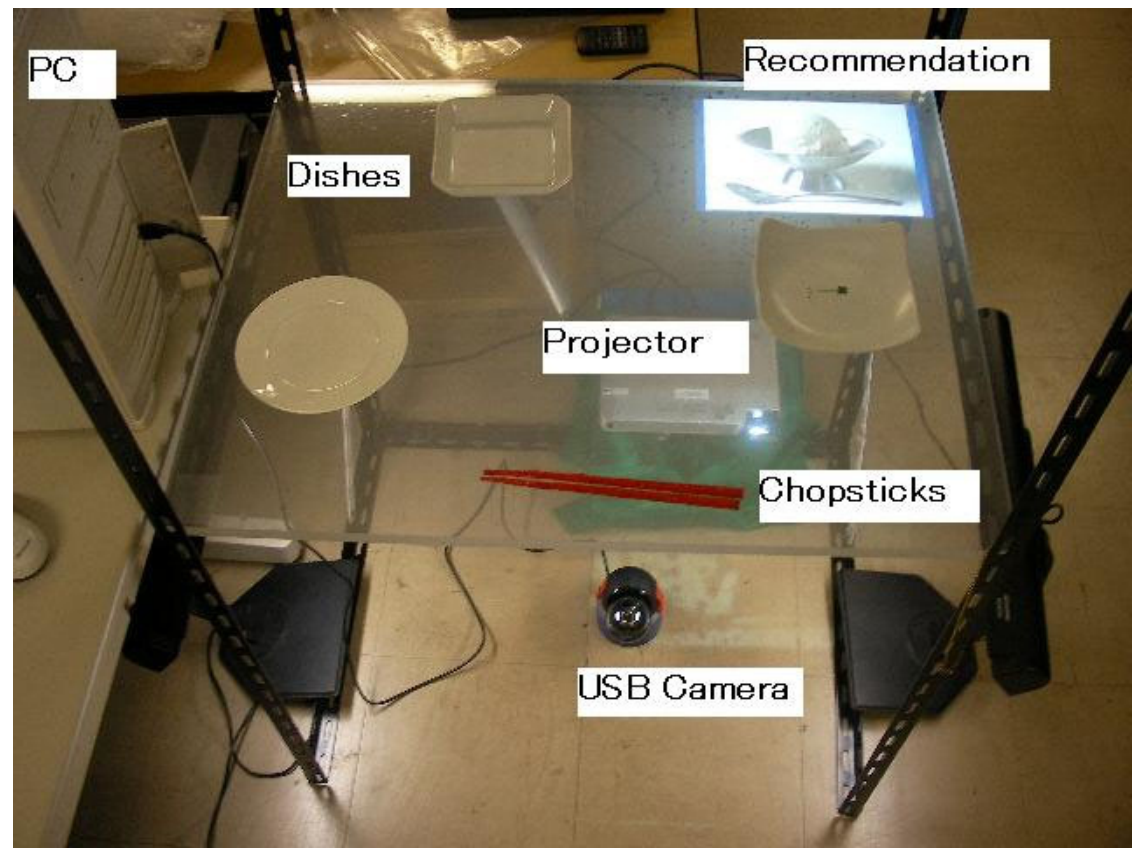

Fig. 2. Future Ding Table overview 


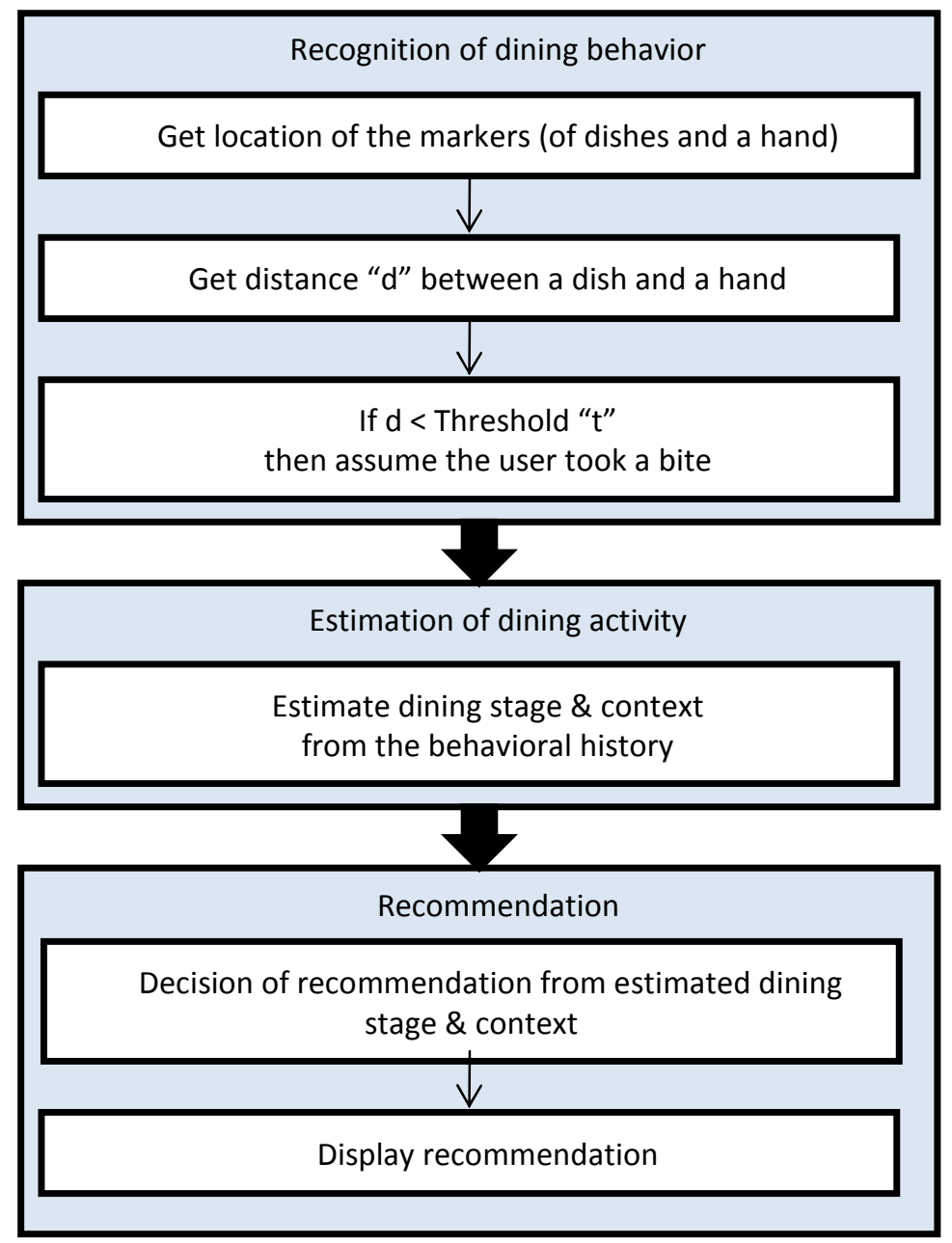

Fig. 3. Future Dining Table algorithm

Dining activity includes handling of dishes and cutleries, i.e. physical objects. Therefore use of software alone is not enough for supporting dining environment. This is different from some other business activities that can be completed by computers and the networks. To recognize the user's dining status, we need to detect dishes and cutleries, and also need to use their operated history.

We propose the Future Dining Table (FDT) that recognizes dining activity of a user in real time, and recommends another dish for additional order according to the dining status. The system is assumed to be used in a restaurant where additional dishes are usually ordered. It is assumed to replace or to help waiters when human resource becomes more precious. 


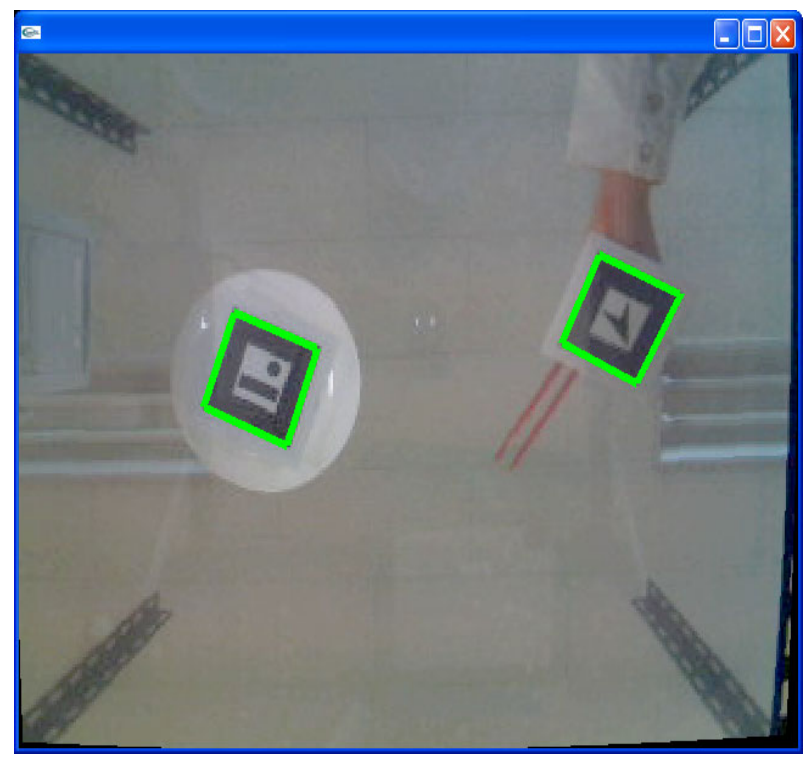

(a)

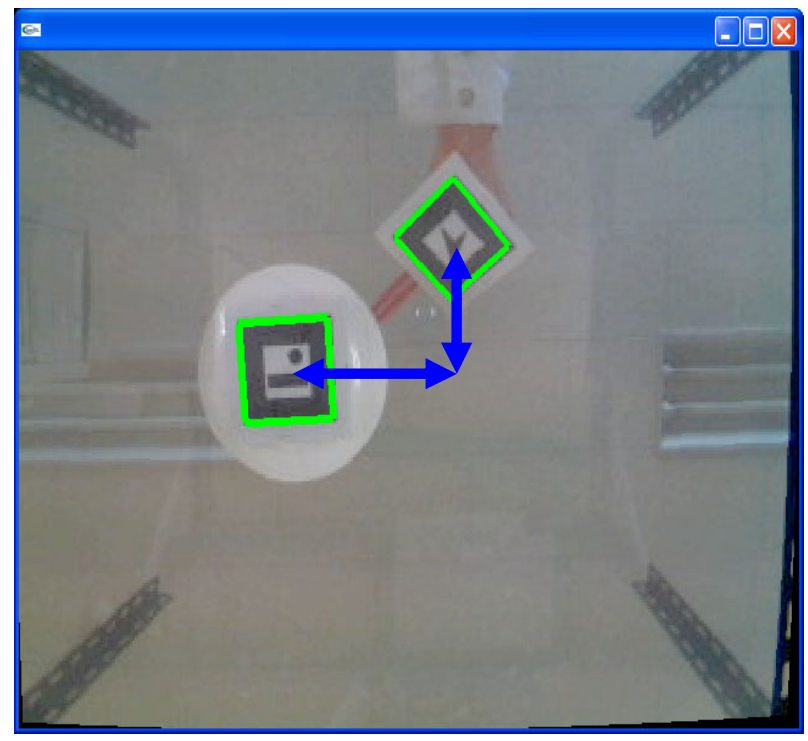

(b)

Fig. 4. Dining activity recognition

(a) Recognition of the visual markers

(b) Closeness of a dish and a hand means a bite 
The picture of FDT is shown in Figure 1. The FDT system overview from a user is shown in Figure 2. From the dining recognition to the dish recommendation is processed mainly in 3 steps. They are the recognition of dining behavior, the estimation of dining activity, and recommendation (Figure 3). Each process is explained in the following subsections.

\subsection{Recognition of Dining Behavior}

As in shown in Figure 2, the table is a transparent $15 \mathrm{~mm}$ thick acrylic board with $60 \mathrm{~cm}$ depth and $75 \mathrm{~cm}$ width. The board is sealed by the transparent screen sheet for video projection (Kimoto Co,Ltd. Dilad Screen T40SI-40) so that the recommendation can be displayed on the table. Each physical dish has a visual marker, for which ARToolkit [14] is used, on its bottom.

The user also attaches the visual marker on his/her hand with chopsticks. The markers are recognized from the image taken by a USB camera (Logicool QVR-13R). The video image from the camera is $320 \times 240$ (pixel) and $15 \mathrm{fps}$, which covers the table. 1pixel of the image is set to $2 \mathrm{~mm}$ in the real world in this condition.

Dining behavior is recognized as the recognition of each dish and the distance between a dish and a hand. The user always uses chopsticks when eating, which is normal in Japanese dining. The hand holding the chopsticks moves to a dish closely when the user takes an eating action. The system recognizes this movement as a bite, a unit of eating. Figure 4 shows the recognition process. The visual markers are recognized as in Figure 4 (a). When the marker of a hand (with chopsticks) and the marker of a dish come close enough as in Figure 4 (b), it is recognized as a bite. Currently, it is recognized as a bite when the distance is less than 80 pixels $(160 \mathrm{~mm})$ in the width direction and is less than 100 pixels $(200 \mathrm{~mm})$ in the depth direction. These values are determined by experience. If the threshold distance is set closer, judgment becomes more severe. If it is set more distant, judgment becomes more relaxed.

Table 1. Example menus and the number of bites for finishing

\begin{tabular}{|c|c|}
\hline Menu & Number of bites for finishing \\
\hline \hline Fried chicken (Oily) & 10 \\
\hline Salad & 20 \\
\hline $\begin{array}{c}\text { Kimchi one-pot dish } \\
\text { (Spicy soup) }\end{array}$ & 30 \\
\hline
\end{tabular}

\subsection{Estimation of Dining Activity}

What the user eats is known from the dining behavior explained in 3.1. To know how much the user eats, a possible method is to measure the weight of each dish as in the related research [9]. Without such a mechanism, another method may be the use of history of bites. If the number of bites to finish a dish is known, how much remains on the dish can be estimated from the bite counts to the dish. Investigation is needed to know the former factor. It may also depend on the user and other contexts. Here we 
prepared 3 example menus and assumed the number of bites to finish the dish for the prototype, which is shown in Table 1. By using the history of bites to each dish, more detailed dining activity can be estimated than using the dining behavior only.

\subsection{Recommendation}

Another dish is recommended using the result of the estimation of dining activity. There are a number of methods for recommendation. Because recommendation algorithm itself is not the focus of this research, we have applied a simple rule-based recommendation for the current FDT. The system displays recommendation according to the operation of physical objects, which has not been exploited yet. Example conditions and the dishes of recommendation are shown in Table 2. With the detailed recognition of dining status and the investigation of actual relation between the condition and the ordered dish, the rule could be refined.

Presentation of recommended dishes is another issue of research. The current system displays the picture of the recommended dish on the table by using a video projector (CASIO XJ-S46).

Table 2. Example rules for recommendation

\begin{tabular}{|c|c|}
\hline Condition & Dish of recommendation \\
\hline \hline $\begin{array}{c}\text { All dishes are less than } 20 \% \text { and } \\
\text { more than } 3 \text { consecutive bites of } \\
\text { fried chicken in the recent } 15 \text { bites }\end{array}$ & Sherbet \\
\hline $\begin{array}{c}\text { More than } 10 \text { bites of kimchi one- } \\
\text { pot dish in the recent 15 bites }\end{array}$ & Milky ice cream \\
\hline $\begin{array}{c}\text { Less than 25\% of Kimchi one-pot } \\
\text { dish }\end{array}$ & Rice for Soupy Rice \\
\hline
\end{tabular}

\section{Initial Evaluation of Dining Activity Recognition}

We have developed the FDT prototype as described. We have confirmed the system works by using the example settings. We have also conducted initial evaluation of dining activity recognition of the system.

The subject was 3 right-handed male university students aged 22 to 24 . All were the first time users of the system. They were asked to eat normally as in everyday. 3 dishes were set on the table as shown in Figure 5. A snack of small pieces was chosen as the food on the dishes because we could control the number of bites by this. 8 pieces of the snack were set on each dish. This meant a subject bit 24 times. The dining behavior was videotaped. The record by the FDT was compared with the videotaped behavior, which provided the correct answer.

The result is shown in Table 3. Precision, recall and F-measure were used as the measures. These are originally from information retrieval, and have become generally used as the measure of such evaluation. Precision is defined as true positive / true positive + false positive. When different dish from the actual dish is recorded by the 
system, precision decreases. Recall is defined as true positive / true positive + false negative. When there is no record while there was an actual bite, recall decreases. F-measure is defined as the harmonic mean of precision and recall; $\mathrm{F}=2$ / $(1 /$ Precision $+1 /$ Recall $)$. It is used to represent the performance of both precision and recall in a single measure.

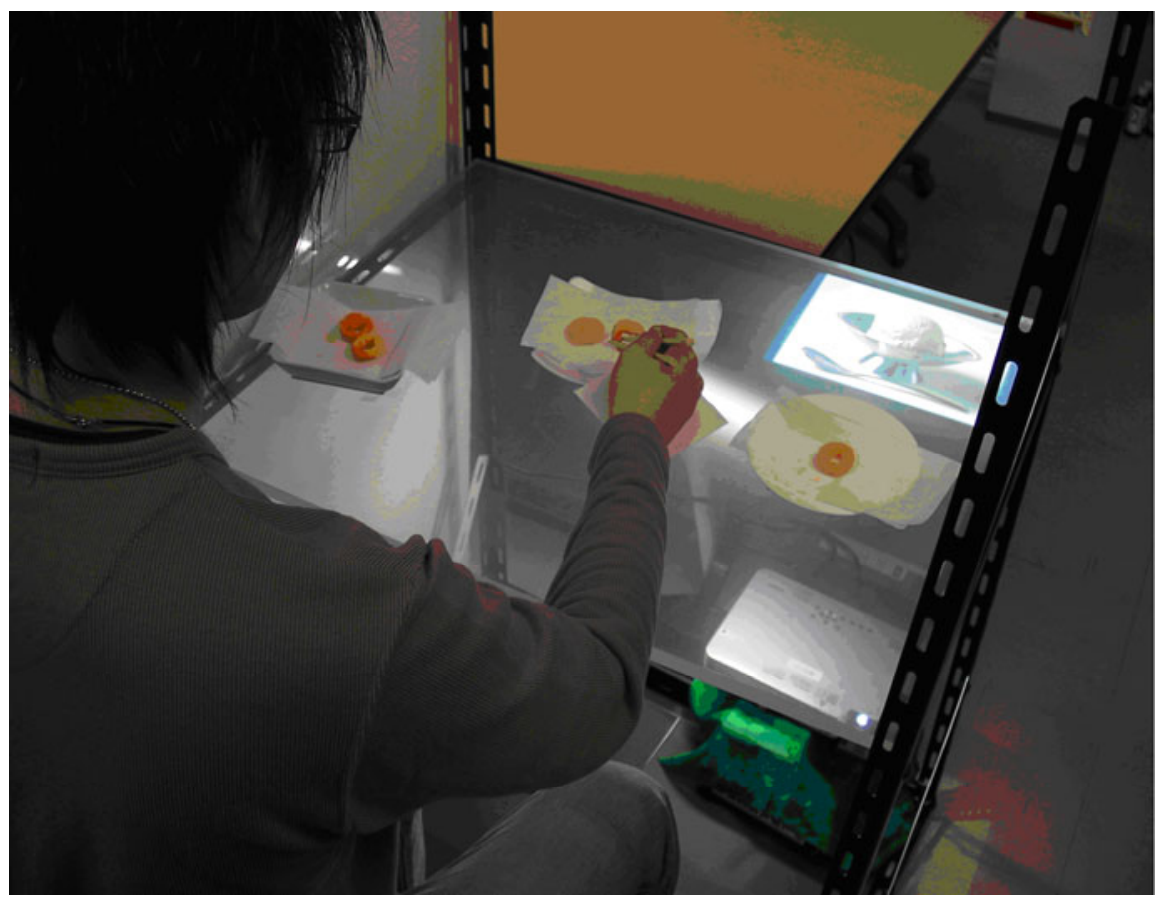

Fig. 5. Future Dining Table in use

Table 3. Result of the dining activity (bite) recognition

\begin{tabular}{|c|c|c|c|}
\hline Subject & Precision & Recall & F-measure \\
\hline \hline $\mathrm{A}$ & .95 & .79 & .86 \\
\hline $\mathrm{B}$ & .82 & .75 & .78 \\
\hline $\mathrm{C}$ & .68 & .54 & .60 \\
\hline Average & .82 & .69 & .75 \\
\hline
\end{tabular}

There was a little dispersion by the subjects. Low recall rate of subject $\mathrm{C}$ was because of his unique form of using chopsticks. Usually people pinch food with the chopsticks, but he laid down them and scooped the snacks. The recall was .69 and the precision .82 on the average, resulting .75 of F-measure. It could be acceptable taking 
into account that the service provided by the system is not mission-critical, although the author does not know of any similar evaluation.

\section{Conclusion}

Future Dining Table was proposed, designed, and the prototype has been implemented. The FDT recognizes dining activity by a camera and the visual markers, which are fairly simple and inexpensive equipments. It can be improved by the application of image recognition technique because the current system requires the user to put a visual marker. By making use of the history of physical objects, FDT can recommend additional dish to order in the right timing of eating. Considering recent and future shortage of labor power, it will become more difficult to keep good employees who are capable of recommending another dish with caring the dining status of the customers. The system is expected to be useful as a substitute of a food server in the kind of restaurants where additional dishes are often ordered. For the future research, we will improve the prototype and will extend the system to better support dining activity including interpersonal communication.

Acknowledgments. The author would like to thank Yuuki Seto for his contribution to the development of FDT. This research was partially supported by the JSPS Grant-inAid for scientific research 22500104, 2010.

\section{References}

1. Ministry of Internal Affairs and Communications of Japan, The Panel on ICT Growth, Final x ICT Vision Report (2008) (in Japanese),

http://www.soumu.go.jp/joho_tsusin/eng/Releases/Telecommunic ations/news080703_3.html, http://www.soumu.go.jp/s-news/2008/pdf/080703_6_bt2.pdf

2. Ishii, H., Ullmer, B.: Tangible Bits: Towards Seamless Interfaces between People, Bits and Atoms. In: Proc. CHI 1997, pp. 234-241 (1997)

3. Wellner, P.: Interacting with paper on the digital desk. Communications of the ACM 36(7), 86-96 (1993)

4. Matsushita, M., Hijikata, Y.: Sugihara, Survey of tabletop systems. Journal of Human Interface Society 9(1), 35-58 (2007)

5. Koike, H., Kobayashi, Y., Sato, Y.: Integration of Paper and Digital Information and Real Time Interaction by hand on Augmented Desk System. Transactions of Information Processing Society of Japan 42(3), 577-585 (2001)

6. Rekimoto, J.: SmartSkin: An Infrastructure for Freehand Manipulations on Interactive Surfaces. In: Proc. CHI 2002, pp. 113-120 (2002)

7. Amano, K., Nishimoto, K.: pHotOluck: Communication Activating System at A Dining Table by Projecting Pictures on Dishes. IPSJ SIG Notes 2004(31), 103-108 (2004)

8. Gao, J., Haupymann, G.A., Bharucha, A., Wactlar, D.H.: Dining Activity Analysis Using a Hidden Markov Model. In: Proceedings of the 17th International Conference on Pattern Recognition (ICPR), vol. 2, pp. 915-918 (2004) 
9. Kawashima, T., Tanisugi, Y., Mitsudo, Y.: Dining Monitoring System Using Sensing Tray and ID-ware, IEICE technical report. Welfare Information Technology 106(285), 61-66 (2006)

10. Watanabe, K., Takeuchi, T., Inoue, T., Okada, K.: Face-to-face collaboration system that identifies individual user. IEICE Transactions on Information and Systems J91-D(12), 2755-2764 (2008)

11. Ministry of Education, Culture, Sports, Science and Technology of Japan, Council for Science and Technology, Toward a nation with intellectual presence (1999) (in Japanese), http://www.mext.go.jp/b_menu/shingi/12/gakujutu/toushin/9906 $01 . \mathrm{htm}$

12. Norman, D.A.: Emotional Design. Basic Books, New York (2004)

13. Cute Interactive Media - Workshop on Designing Cute Interactive Media (2008), http: / / kawaii.wikidot.com/

14. ARToolKit Home Page, http: / /www. hitl. washington. edu/artoolkit/ 